\title{
Poly(N-isopropylacrylamide-co-methacrylic acid) microgel stabilized copper nanoparticles for catalytic reduction of nitrobenzene
}

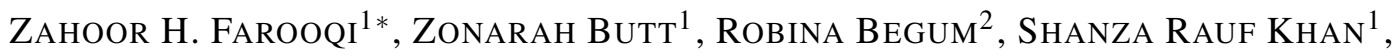 \\ AHSAN SHARIF ${ }^{1}$, EJAZ AHMED ${ }^{1}$ \\ ${ }^{1}$ Institute of Chemistry, University of the Punjab, New Campus Lahore 54590, Pakistan \\ ${ }^{2}$ Centre for Undergraduate Studies, University of the Punjab, New Campus Lahore 54590, Pakistan
}

\begin{abstract}
Poly(N-isopropylacrylamide-co-methacrylic acid) microgels [p(NIPAM-co-MAAc)] were synthesized by precipitation polymerization of $\mathrm{N}$-isopropylacrylamide and methacrylic acid in aqueous medium. These microgels were characterized by dynamic light scattering and Fourier transform infrared spectroscopy. These microgels were used as micro-reactors for in situ synthesis of copper nanoparticles using sodium borohydride $\left(\mathrm{NaBH}_{4}\right)$ as reducing agent. The hybrid microgels were used as catalysts for the reduction of nitrobenzene in aqueous media. The reaction was performed with different concentrations of catalyst and reducing agent. A linear relationship was found between apparent rate constant $\left(\mathrm{k}_{\mathrm{app}}\right)$ and amount of catalyst. When the amount of catalyst was increased from 0.13 to $0.76 \mathrm{mg} / \mathrm{mL}$ then $\mathrm{k}_{\text {app }}$ was increased from 0.03 to $0.14 \mathrm{~min}^{-1}$. Activation parameters were also determined by performing reaction at two different temperatures. The catalytic process has been discussed in terms of energy of activation, enthalpy of activation and entropy of activation. The synthesized particles were found to be stable even after 14 weeks and showed catalytic activity for the reduction of nitrobenzene.
\end{abstract}

Keywords: catalysis; copper; microgels; nanoparticles

(C) Wroclaw University of Technology.

\section{Introduction}

Metal nanoparticles have gained worldwide attention due to their diverse applications in fields of sensing [1-3], photonics [4], medical [5], and catalysis [6-8]. Metal nanoparticles are considered as excellent catalyst due to high surface to volume ratio and quantum effects. Mostly, nanoparticles of silver $(\mathrm{Ag})$ [9], gold $(\mathrm{Au})$ [10], platinum $(\mathrm{Pt})$ [11] and palladium $(\mathrm{Pd})$ [12] are used in the field of catalysis. But these are expensive metals. It is not economical to use such expensive metals as catalysts on industrial scale. Therefore, it is a need of time that we should have cheap but efficient catalysts. Copper $(\mathrm{Cu})$ nanoparticles are cheap and highly conducting, therefore, they are enormously being used in nano electric, photonic [13], catalytic [14] and

*E-mail: zhfarooqi@gmail.com biological fields [15, 16]. Wu et al. [17] have synthesized $\mathrm{Cu}$ nanoparticles using cetyltrimethylammonium bromide surfactant as stabilizing agent. Cioffi et al. [18] fabricated $\mathrm{Cu}$ nanoparticles within poly-vinyl-methyl ketone films for application in biomedical field. Park et al. [19] synthesized $\mathrm{Cu}$ nanoparticles of different size and size distribution by polyol method. Santanalakhshmi et al. [14] synthesized non-responsive copper-poly(ethylene glycol) and copper-carboxy methyl cellulose, and responsive copper-poly(N-vinyl pyrolidene) hybrid polymers for catalysis of nitrobenzene (NB) and its derivatives. $\mathrm{Cu}$ nanoparticles fabricated in poly(2acrylamido-2-methyl-1-propansulfonic acid) hybrid hydrogels were prepared by Sahiner et al. [20] for catalysis of nitroarenes. However, in vivo synthesis of $\mathrm{Cu}$ nanoparticles within responsive microgels has not been reported yet. $\mathrm{Cu}$ nanoparticles are not so much stable and they are prone to surface oxidation [21]. Surface oxidation limits the 
use of $\mathrm{Cu}$ nanoparticles in optical, electrical, catalytic and other surface related properties for beneficial purposes. Microgels can successfully stabilize $\mathrm{Cu}$ nanoparticles due to the well-known donoracceptor concept [22]. Pendant amino and carboxylate groups in $\mathrm{N}$-isopropylacrylamide (NIPAM) and ionic monomers based microgels act as ligands and form a complex with $\mathrm{Cu}$ metal nanoparticles by donating electrons to nanoparticles. Microgels are responsive polymers, therefore, they can successfully control the size, inter-particle spacing and refractive index sensitivity of $\mathrm{Cu}$ nanoparticles due to their responsive nature and structure. Catalysis is a size and surface dependent application of nanoparticles, and microgels can successfully control the size of nanoparticles during in vivo chemical reduction synthesis of nanoparticles [23, 24]. Moreover, microgels are sensitive to $\mathrm{pH}$, temperature and ionic strength. Therefore, they can tune the catalytic activity of $\mathrm{Cu}$ nanoparticles in response to variable $\mathrm{pH}$, temperature and ionic strength [25-28].

NB is a pollutant because it causes vomiting, headache, liver diseases, skin irritation and anaemia in human beings [29, 30]. It is continuously released into environment from paint, pesticides and synthetic industries. Therefore, its rapid conversion into a useful and less toxic product is of great importance. NB is reduced into less harmful product, amino-benzene (AB), commonly known as aniline, using nanoparticles as a catalyst. Aniline is used in solar cells [31], conducting polymers [32], corrosion resistant agents [33]. According to best of our knowledge, there has been no report on catalytic reduction of $\mathrm{NB}$ into $\mathrm{AB}$ in aqueous medium using $\mathrm{Cu}$ nanoparticles containing multi-responsive microgels in the literature. In the present study we are going to report catalytic reduction of NB into $\mathrm{AB}$ using $\mathrm{Cu}-\mathrm{p}$ (NIPAM-coMAAc) hybrid microgels.

Here in, $\mathrm{Cu}$ nanoparticles were synthesized using poly $(\mathrm{N}$-isopropylacrylamide-co-methacrylic acid) microgels [p(NIPAM-co-MAAc)] as microreactors by in situ reduction. Copper-poly(Nisopropylacrylamide-co-methacrylic acid) hybrid microgels [Cu-p(NIPAM-co-MAAc)] were used for catalytic reduction of NB into $\mathrm{AB}$ in an aqueous medium. The effect of different experimental parameters: concentration of sodium borohydride $\left(\mathrm{NaBH}_{4}\right)$, catalyst dosage and temperature on the value of apparent rate constant $\left(\mathrm{k}_{\mathrm{app}}\right)$ for catalytic reduction was investigated. Kinetics of the process has been also discussed in terms of Arrhenius and Eyring parameters in this study.

\section{Experimental}

\subsection{Materials}

$\mathrm{N}$-isopropylacrylamide (NIPAM), methacrylic acid (MAAc), N,N-methylenebis (acrylamide) (BIS), sodium dodecylsulfate (SDS), copper chloride $\left(\mathrm{CuCl}_{2} \cdot 2 \mathrm{H}_{2} \mathrm{O}\right)$, ammonium persulfate (APS), sodium borohydride $\left(\mathrm{NaBH}_{4}\right)$ and nitrobenzene (NB) were purchased from Sigma Aldrich. All chemicals except MAAc were used as such without any further purification. Hydroquinone inhibitor was removed from MAAc by vacuum filtration through alumina under reduced pressure. Deionized water was used for all solution preparation, chemical reactions, dialysis, catalytic reduction and dynamic light scattering measurements.

\subsection{Synthesis of poly(N-isopropy- lacrylamide-co-methacrylic acid) microgels}

p(NIPAM-co-MAAc) microgels were synthesized by precipitation polymerization of NIPAM and MAAc as previously reported by our group [34, 35]. 1.08 g NIPAM, $42 \mu \mathrm{L}$ MAAc, $0.08 \mathrm{~g}$ BIS and $0.05 \mathrm{~g}$ SDS were dissolved in $95 \mathrm{~mL}$ of distilled water in a $250 \mathrm{~mL}$ three necked round bottom flask equipped with a nitrogen gas inlet and a condenser. The reaction mixture was stirred and heated to $70{ }^{\circ} \mathrm{C}$ under constant nitrogen purge. After the maintenance of temperature at $70{ }^{\circ} \mathrm{C}$ for $30 \mathrm{~min}, 5 \mathrm{~mL}$ of freshly prepared $0.05 \mathrm{M}$ APS solution was added into the reaction mixture. After 5 hours, p(NIPAM-co-MAAc) microgels were cooled and dialyzed using Spectra/Por molecular porous membrane tubing (Fisher Scientific) having MWCO 12000 to 14000. Dialysis was performed for 6 days with daily exchange of water. 


\subsection{Synthesis of copper-poly(N-iso- propylacrylamide-co-methacrylic acid) hybrid microgels}

$\mathrm{Cu}$-p(NIPAM-co-MAAc) hybrid microgels were synthesized by in situ reduction of copper ions within the framework of $p$ (NIPAM-co-MAAc) microgels. $9 \mathrm{~mL}$ of $\mathrm{p}$ (NIPAM-co-MAAc) microgel dispersion, $46 \mathrm{~mL}$ water and $37 \mathrm{~mL} \mathrm{CuCl}{ }_{2} \cdot 2 \mathrm{H}_{2} \mathrm{O}$ $(1 \mathrm{mM})$ solution were added into a three necked round bottom flask $(250 \mathrm{~mL})$ equipped with a nitrogen gas inlet and a condenser. The reaction mixture was stirred for 30 minutes at room temperature. Then $8 \mathrm{~mL}$ of $34 \mathrm{mM} \mathrm{NaBH}_{4}$ was added dropwise and the reaction mixture was further stirred for 2 hours. Cu-p(NIPAM-co-MAAc) hybrid microgels were dialyzed against water for half an hour using Spectra/Por ${ }^{\circledR}$ molecular porous membrane.

\subsection{Catalytic reduction of nitrobenzene}

The spectrum of NB was scanned in the range of 200 to $500 \mathrm{~nm}$ and its $\lambda_{\max }$ was found at $265 \mathrm{~nm}$. $\mathrm{NB}$, hybrid microgel dispersion and $\mathrm{NaBH}_{4}$ solution were taken in a cuvette and their spectra were scanned with a UVD-3500 spectrophotometer in 200 to $350 \mathrm{~nm}$ wavelength range. The spectra were scanned after every minute till the absorbance at $265 \mathrm{~nm}$ became constant. Catalytic reduction of NB was performed under different conditions of temperature, concentration of $\mathrm{NaBH}_{4}$ and catalyst dosage as given in Table 1.

\subsection{Characterization}

Fourier transform infrared (FT-IR) spectra of microgels were recorded on Shimadzu Prestige-21 FT-IR spectrophotometer having frequency range of 650 to $4000 \mathrm{~cm}^{-1}$ and resolving power of $4 \mathrm{~cm}^{-1}$. Dynamic light scattering (DLS) measurements were performed by using commercial LLS spectrometer (B1-200SM) equipped with a digital autocorrelator (B1-9000AT). $22 \mathrm{~mW}$ uniphase cylindrical Helium-Neon laser of a wavelength $637 \mathrm{~nm}$ was used as a source of light. Double beam UVD-3500 of Labomed Inc, was used to monitor the reduction of $\mathrm{NB}$.

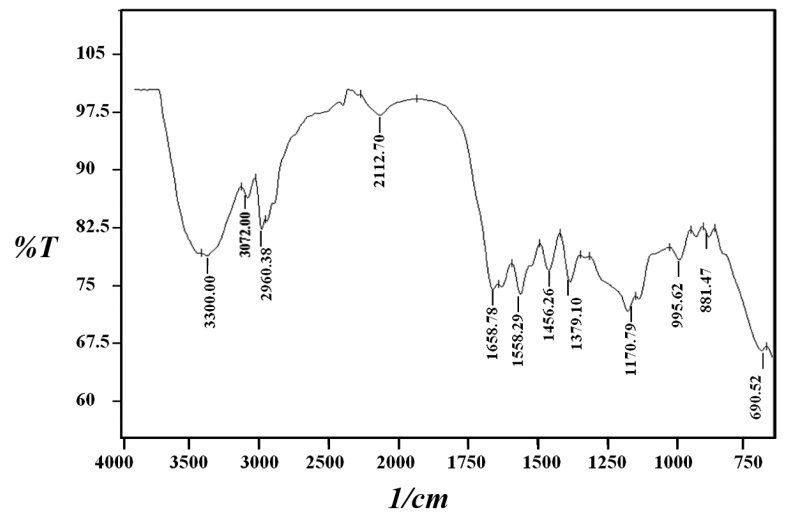

Fig. 1. FT-IR spectra of p(NIPAM-co-MAAc) copolymer microgels.

\section{Results and discussion}

\subsection{FT-IR analysis of poly( $\mathrm{N}$-iso- propylacrylamide-co-methacrylic acid) microgels}

The FT-IR spectrum of $p$ (NIPAM-co-MAAc) microgels shown in Fig. 1 was used to confirm the chemical structure of the polymer microgels. The FT-IR spectrum does not possess any absorption band around 1600 to $1650 \mathrm{~cm}^{-1}$ which indicates the absence of carbon-carbon double bond $(\mathrm{C}=\mathrm{C})$ in the structure of the $\mathrm{p}($ NIPAMco-MAAc) microgels [36]. Both NIPAM and MAAc contain $\mathrm{C}=\mathrm{C}$ bonds, while $\mathrm{p}$ (NIPAM-coMAAc) microgels posses no $\mathrm{C}=\mathrm{C}$ bond. Therefore, absence of band around $1600 \mathrm{~cm}^{-1}$ indicates that polymerization has occurred at $\mathrm{C}=\mathrm{C}$ bond. Absorption bands around 1558.48, 1658.78 and $3360.0 \mathrm{~cm}^{-1}$ were also observed which, respectively, indicates incorporation of $-\mathrm{CH}_{2}, \mathrm{C}=\mathrm{O}$ and $\mathrm{N}-\mathrm{H}$ (stretching) groups within the structure of the synthesized p(NIPAM-co-MAAc) microgels. Absorption band of $\mathrm{N}-\mathrm{H}$ bond is broad which indicates the presence of bonded water molecules within the microgels [26]. Luo et al. [37] used FT-IR technique to analyze the structure of poly $(\mathrm{N}$-isopropylacrylamide-coacrylic acid) and poly(N-isopropylacrylamide-co40-aminobenzo-18-crown-6) microgels. They also observed similar bands in FT-IR spectra of microgels. 
Table 1. Various compositions of reaction mixtures used to study different parameters of catalytic reduction of $0.05 \mathrm{mM}$ NB.

\begin{tabular}{ccccc}
\hline Parameters & $\begin{array}{c}{\left[\mathrm{NaBH}_{4}\right]} \\
{[\mathrm{mM}]}\end{array}$ & $\begin{array}{c}{[\mathrm{Cu}-\mathrm{p}(\mathrm{NIPAM}-\mathrm{co}-\mathrm{MAAc})]} \\
{[\mathrm{mg} / \mathrm{mL}]}\end{array}$ & $\begin{array}{c}\text { Temperature } \\
{\left[{ }^{\circ} \mathrm{C}\right]}\end{array}$ & $\begin{array}{c}\mathrm{k}_{\text {app }} \\
{\left[\mathrm{min}^{-1}\right]}\end{array}$ \\
\hline \hline \multirow{2}{*}{ Hybrid microgel } & 5 & 0.13 & 18 & 0.091 \\
& 5 & 0.16 & 18 & 0.199 \\
\hline \multirow{2}{*}{$\mathrm{NaBH}_{4}$} & 5 & 0.33 & 18 & 0.210 \\
& 7 & 0.33 & 18 & 0.243 \\
& 8 & 0.33 & 18 & 0.264 \\
& 9 & 0.33 & 18 & 0.261 \\
\hline \multirow{2}{*}{ Temperature } & 5 & 0.16 & 18 & 0.199 \\
& 5 & 0.16 & 33 & 0.264 \\
\hline
\end{tabular}

\section{2. pH sensitivity of poly(N-iso-} propylacrylamide-co-methacrylic acid) microgels

Effect of $\mathrm{pH}$ on hydrodynamic radius $\left(\mathrm{R}_{\mathrm{h}}\right)$ of $\mathrm{p}$ (NIPAM-co-MAAc) microgel particles is shown in Fig. 2. It is observed that $R_{h}$ increases with an increase in $\mathrm{pH}$ due to successive ionization of carboxyl groups of MAAc. Fig. 2 shows that $\mathrm{R}_{\mathrm{h}}$ of microgel particles is small when $\mathrm{pH}$ of the medium is smaller than that of the pKa of MAAc ( 4.86) [9]. At low $\mathrm{pH}$, carboxyl groups are in protonated state and electrostatic repulsive forces are absent. Protonated carboxyl groups are also less hydrophilic as compared to negatively charged carboxylate ions $\left(-\mathrm{COO}^{-}\right)$. Thus, due to absence of repulsive forces and less hydrophilicity of protonated carboxyl groups, the microgels contain small number of water molecules at low $\mathrm{pH}$ and the value of $\mathrm{R}_{\mathrm{h}}$ is small as the result [38]. When the $\mathrm{pH}$ of the medium is greater than that of $\mathrm{pKa}$ of MAAc then deprotonation of carboxyl groups starts. Due to this ionization, the microgel network not only becomes hydrophilic but the polymer network of microgels also pushes apart due to appearance of electrostatic repulsive forces. Thus, water molecules move into the microgel particles creating osmotic pressure and this osmotic pressure is compensated by an increase in the value of $R_{h}$ [39]. The increase in the value of $R_{h}$ becomes more significant when the $\mathrm{pH}$ of the medium is around 4.5 to 5 because almost all carboxyl groups get ionized around these
$\mathrm{pH}$ values. The value of $\mathrm{R}_{\mathrm{h}}$ is almost the same at 6 to $10 \mathrm{pH}$ because all carboxyl groups are ionized at this condition. The increase in $\mathrm{R}_{\mathrm{h}}$ by increase in $\mathrm{pH}$ helps in fabrication of in situ synthesized $\mathrm{Cu}$ metal nanoparticles in the microgel network, as ionized carboxyl groups of MAAc electrostatically pull metal ions into the sieves of microgels [40]. Moreover, $\mathrm{Cu}$ nanoparticles fabricated p(NIPAMco-MAAc) microgels were also used as a catalyst for reduction of $\mathrm{NB}$ at high $\mathrm{pH}$ in aqueous medium as described in the later sections. DLS study revealed that the microgels are in fully swollen state at high $\mathrm{pH}$ so the reagents for catalysis can easily diffuse within the polymer network of the microgels. Thus, nanoparticles are easily accessible for reagents and the catalysis can be done successfully.

\subsection{Catalytic reduction of nitrobenzene}

Catalytic reduction of NB was selected as a model reaction to investigate the catalytic activity of $\mathrm{Cu}-\mathrm{p}$ (NIPAM-co-MAAc) hybrid microgels for reduction of nitroarenes. Catalytic reduction of $\mathrm{NB}$ was monitored by UV-Vis spectrophotometer because the reactant $\mathrm{NB}$ and the product $\mathrm{AB}$, both are UV-Vis absorbers. With the progress of reaction, absorbance at $\lambda_{\max }$ of $\mathrm{NB}(265 \mathrm{~nm})$ decreases along with an increase in absorbance at $\lambda_{\max }$ of $A B$ $(230 \mathrm{~nm})$ as shown in Fig. 3. Catalytic reduction of NB obeys pseudo first order kinetics because $\mathrm{NaBH}_{4}$ is taken in excess. Therefore, $\ln \left(\mathrm{C}_{t} / \mathrm{C}_{\mathrm{o}}\right)$ was 


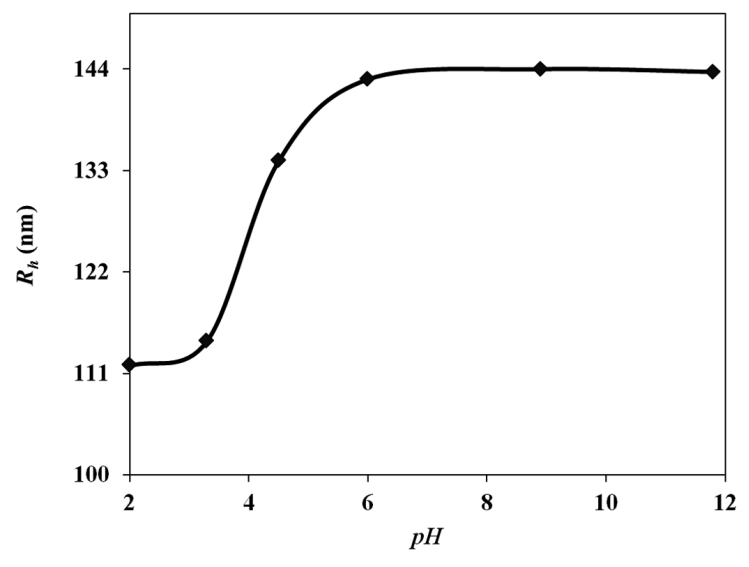

Fig. 2. The change in $R_{h}$ of $p(N I P A M-c o-M A A c)$ microgels with change in $\mathrm{pH}$ at $25^{\circ} \mathrm{C}$.

plotted versus time and the value of $\mathrm{k}_{a p p}$ was determined during the whole study, where $\mathrm{C}_{\mathrm{t}}$ and $\mathrm{C}_{\mathrm{o}}$ are concentrations of $\mathrm{NB}$ at any time and at $0 \mathrm{~s}$, respectively.

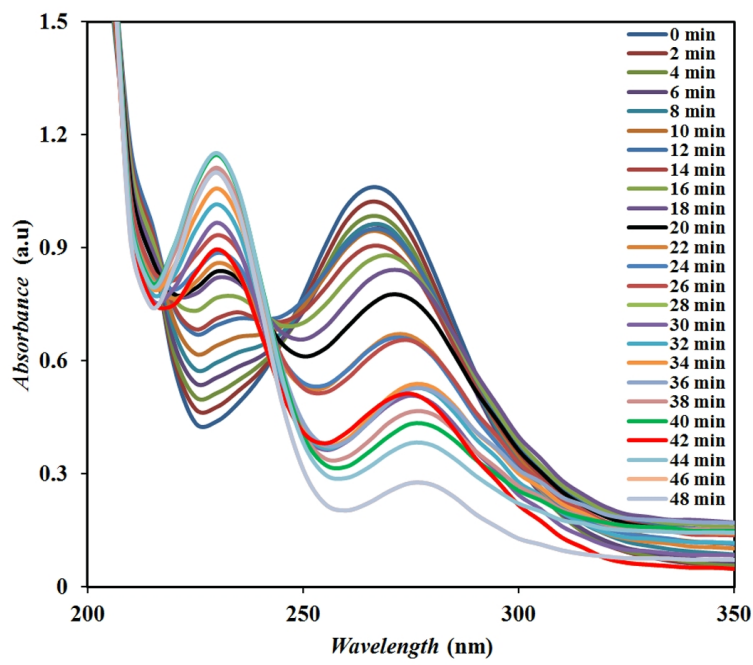

Fig. 3. UV-Vis spectra of catalytic reduction of NB in presence of Cu-p(NIPAM-co-MAAc) hybrid microgels in aqueous medium (conditions: $[\mathrm{NB}]=0.05 \mathrm{mM},[\mathrm{Cu}-\mathrm{p}$ (NIPAM-co-MAAc) $]=$ $0.13 \mathrm{mg} / \mathrm{mL},\left[\mathrm{NaBH}_{4}\right]=5 \mathrm{mM}$ and temperature $=18^{\circ} \mathrm{C}$ with total volume $2.5 \mathrm{~mL}$ in cuvette).

In another experiment, reduction of $\mathrm{NB}$ was monitored in the absence of Cu-p(NIPAM-coMAAc) catalyst and it was observed that absorbance at $265 \mathrm{~nm}$ does not change at all. Actually, metal nanoparticles act as carriers for the transfer of electrons between $\mathrm{NB}$ and $\mathrm{NaBH}_{4}$ [41], therefore, the reaction is kinetically restricted in the absence of catalyst.

\subsubsection{Effect of catalyst dosage on the value of $\mathbf{k}_{\text {app }}$}

Effects of catalyst dosage, concentration of $\mathrm{NaBH}_{4}$ and temperature on the value of $\mathrm{k}_{\text {app }}$ for reduction of NB in the presence of $\mathrm{Cu}$-p(NIPAMco-MAAc) hybrid microgels were studied and their details are given in Table 1.

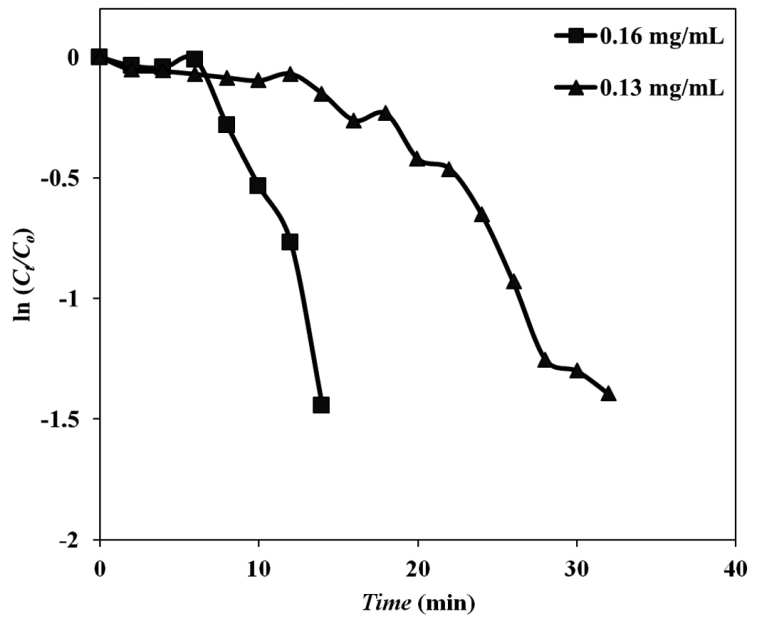

Fig. 4. Plot of $\ln \left(\mathrm{C}_{\mathrm{t}} / \mathrm{C}_{\mathrm{o}}\right)$ versus time for catalytic reduction of $\mathrm{NB}$ in presence of different catalyst dosages (conditions: $[\mathrm{NB}]=0.05 \mathrm{mM},\left[\mathrm{NaBH}_{4}\right]$ $=5 \mathrm{mM}$ and temperature $=18{ }^{\circ} \mathrm{C}$ with total volume $2.5 \mathrm{~mL}$ in cuvette).

Catalytic reduction of NB was studied in the presence of 0.13 and $0.16 \mathrm{mg} / \mathrm{mL}$ dosage of $\mathrm{Cu}-$ $\mathrm{p}$ (NIPAM-co-MAAc) catalyst. A plot of $\ln \left(\mathrm{C}_{\mathrm{t}} / \mathrm{C}_{\mathrm{o}}\right)$ versus time for reduction of $\mathrm{NB}$ under different catalyst dosages is shown in Fig. 4. Initially the value of $\ln \left(\mathrm{C}_{t} / \mathrm{C}_{\mathrm{o}}\right)$ does not change with the passage of time. This time delay is associated with the time taken by reactants to diffuse towards the catalyst surface. Fig. 4 shows that this time delay is more pronounced at low concentrations of catalyst and duration of time delay decreases with an increase in the amount of the catalyst. In case of high concentration of catalyst, reactants can approach the catalyst surface in a short time interval because in this case reactant and catalyst are very close to each other. Therefore, reagents get rapidly 


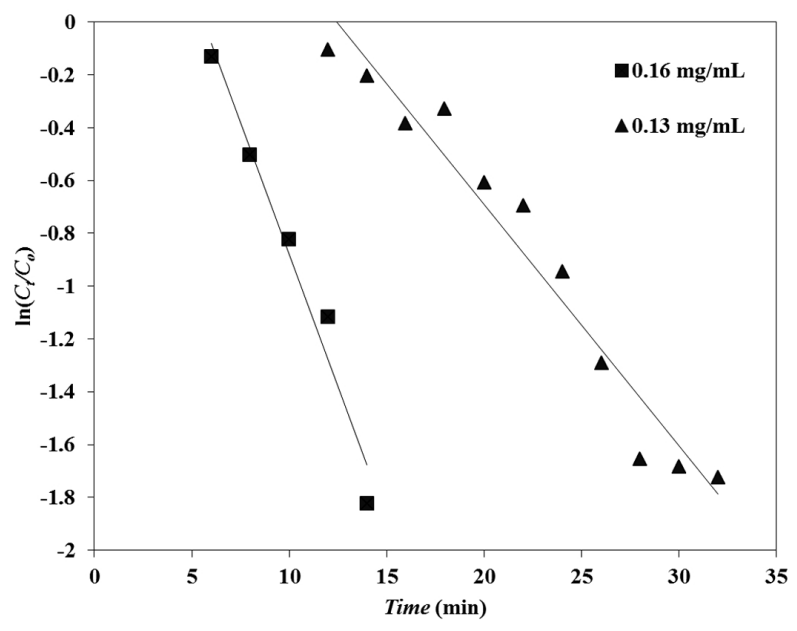

Fig. 5. Linear regions of time dependent plot of $\ln \left(C_{t} / C_{o}\right)$ for catalytic reduction of NB in presence of different catalyst dosages for calculation of kapp. (conditions: $[\mathrm{NB}]=0.05 \mathrm{mM},\left[\mathrm{NaBH}_{4}\right]$ $=5 \mathrm{mM}$ and temperature $=18{ }^{\circ} \mathrm{C}$ with total volume $2.5 \mathrm{~mL}$ in cuvette).

adsorbed on the surface of the catalyst at high catalyst dosage and the catalysis starts immediately. After time delay, the value of $\ln \left(\mathrm{C}_{\mathrm{t}} / \mathrm{C}_{\mathrm{o}}\right)$ decreases with the passage of time. This decrease in value of $\ln \left(\mathrm{C}_{t} / \mathrm{C}_{\mathrm{o}}\right)$ shows that reduction has started and $\mathrm{NB}$ is converting into $\mathrm{AB}$ during the progress of reaction. Plots of linear regions of $\ln \left(\mathrm{C}_{t} / \mathrm{C}_{\mathrm{o}}\right)$ versus time under different catalyst dosages are shown in Fig. 5. The straight line indicates that the reaction follows pseudo first order kinetics. The value of $\mathrm{k}_{\mathrm{app}}$ determined from the slopes of these plots for 0.13 and $0.16 \mathrm{mg} / \mathrm{mL}$ catalyst dosages are 0.091 and $0.199 \mathrm{~min}^{-1}$, respectively, at $18{ }^{\circ} \mathrm{C}$ as given in Table 1 . The rapid reduction of NB at high catalyst dosage is due to the presence of large number of $\mathrm{Cu}$ nanoparticles which provide more surface area for the reduction of NB [9]. Thus, the rate of catalytic reduction increases by increasing the amount of hybrid microgel catalyst. The same behavior was observed by Manesh et al. [8] when they employed Ag nanoparticles distributed in polyaniline bridged silica network for the catalytic reduction of p-nitrophenol. The apparent rate constant calculated in our work is found to be greater than that of other reported values of kapp by using different nanoparticles [42].

\subsubsection{Effect of concentration of sodium boro- hydride on the value of $\mathbf{k}_{\mathrm{app}}$}

Catalytic reduction of NB was also studied under different concentrations of $\mathrm{NaBH}_{4}$ as given in Table 1. 5, 7, 8 and $9 \mathrm{mM} \mathrm{NaBH} 4$ was used to study catalytic reduction of $0.05 \mathrm{mM} \mathrm{NB}$ in the presence of $0.33 \mathrm{mg} / \mathrm{mL}$ catalyst at $18{ }^{\circ} \mathrm{C}$. The values of $\mathrm{k}_{\mathrm{app}}$ are found to be $0.210,0.243,0.264$ and $0.261 \mathrm{~min}^{-1}$ for catalytic reduction of NB using 5, 7, 8 and $9 \mathrm{mM} \mathrm{NaBH}$, respectively. We observed that the value of $\mathrm{k}_{\mathrm{app}}$ increases with an increase in concentration of $\mathrm{NaBH}_{4}$ because the concentration of electron donor species is increasing. We also noted that the increase in the value of $k_{a p p}$ with an increase in concentration of $\mathrm{NaBH}_{4}$ is not so significant because the concentration of $\mathrm{NaBH}_{4}$ is 100 times larger as compared to that of $\mathrm{NB}$ in the reaction mixture [43]. Moreover, the time delay was not observed in case of high concentration of catalyst, i.e. $0.33 \mathrm{mg} / \mathrm{mL}$ because of the availability of the catalyst surface in the closed vicinity of reactants.

\subsubsection{Effect of temperature on the value of $\mathbf{k}_{\text {app }}$}

Effect of temperature on the rate of catalysis reaction was also studied as given in Table 1. Plots of $\ln \left(\mathrm{C}_{\mathrm{t}} / \mathrm{C}_{\mathrm{o}}\right)$ versus time for the catalytic reduction of $\mathrm{NB}$ at 18 and $33{ }^{\circ} \mathrm{C}$ are shown in Fig. 6. The value of $\mathrm{k}_{\mathrm{app}}$ was found to be 0.199 and $0.264 \mathrm{~min}^{-1}$ for reduction at 18 and $33{ }^{\circ} \mathrm{C}$, respectively. It can be seen that the value of $\mathrm{k}_{\text {app }}$ increases with an increase of temperature and the catalyst was found to be more active for reduction at high temperature. This is purely due to Arrhenius behavior of the reaction. The value of $k_{\text {app }}$ increases with an increase of temperature according to Arrhenius equation. Larger number of molecules has an optimum energy of activation at high temperature, thus, reduction occurs more rapidly at high temperature. Therefore, we can say that the rate of reaction increases with an increase in temperature. Arrhenius equation 1 was used for determination of $E_{a}$ and the pre-exponential factor (A) and Eyring equation 2 was used for determination of enthalpy of 
Table 2. Arrhenius and Eyring parameters for reduction reaction of NB catalyzed by Cu-p(NIPAM-co-MAAc) hybrid microgels.

\begin{tabular}{cccccc}
\hline $\begin{array}{c}\mathrm{k}_{\mathrm{app}} \\
{\left[\mathrm{min}^{-1}\right]}\end{array}$ & $\begin{array}{c}\mathrm{T} \\
{[\mathrm{K}]}\end{array}$ & $\begin{array}{c}\mathrm{A} \\
{\left[\mathrm{min}^{-1}\right]}\end{array}$ & $\begin{array}{c}\mathrm{E}_{\mathrm{a}} \\
{[\mathrm{J} / \mathrm{mol}]}\end{array}$ & $\begin{array}{c}\Delta \mathrm{H}^{\#} \\
{[\mathrm{~J} / \mathrm{mol}]}\end{array}$ & $\begin{array}{c}\Delta \mathrm{S}^{\#} \\
{\left[\mathrm{~J} \cdot \mathrm{mol}^{-1} \cdot \mathrm{K}^{-1}\right]}\end{array}$ \\
\hline \hline 0.199 & 291 & 250.16 & $1.73 \times 10^{4}$ & $11.47 \times 10^{3}$ & -252.74 \\
\hline 0.264 & 306 & & & &
\end{tabular}

activation $\left(\Delta \mathrm{H}^{\#}\right)$ and entropy of activation $\left(\Delta \mathrm{S}^{\#}\right)$ :

$$
\begin{gathered}
k_{\text {app }}=A e^{-\frac{E_{a}}{R T}} \\
k_{\text {app }}=\frac{k_{B} T}{h} e^{-\left(\frac{\Delta H^{\#}-T \Delta s^{\#}}{R T}\right)}
\end{gathered}
$$

where $\mathrm{k}_{\mathrm{B}}$ is Boltzmann constant whose value is $1.38 \times 10^{-23} \mathrm{~J} / \mathrm{K}$ and $\mathrm{h}$ is Planck constant whose value is $6.626 \times 10^{-34} \mathrm{~J} \cdot \mathrm{s}$ in equation 2 . $\mathrm{R}$ is the general gas constant whose value is $8.314 \mathrm{~J} \cdot \mathrm{mol}^{-1} \cdot \mathrm{K}^{-1}$. The calculated values of Arrhenius and Eyring parameters are given in Table 2. The value of entropy of activation is negative which indicates that the degree of disorderness increases at the catalyst-solution interface during the process of reduction of nitrobenzene. The positive value of enthalpy of activation shows that formation of activated complexes from reactants is an endothermic process.

\section{Conclusions}

We have synthesized p(NIPAM-co-MAAc) microgels by precipitation polymerization of NIPAM nad MAAc. p(NIPAM-co-MAAc) microgels were characterized by FT-IR and DLS. Cu nanoparticles were in vivo synthesized within the framework of p(NIPAM-co-MAAc) microgels by chemical reduction method. These synthesized nanoparticles were then employed as a catalyst for the reduction of NB in aqueous medium. The reaction was performed by varying the amount of catalyst, temperature and concentration of $\mathrm{NaBH}_{4}$. It was observed that the value of $\mathrm{k}_{\text {app }}$ increased, when we increased either concentration of $\mathrm{NaBH}_{4}$, catalyst dosage or temperature. The catalytic reduction of NB became more spontaneous with an increase in

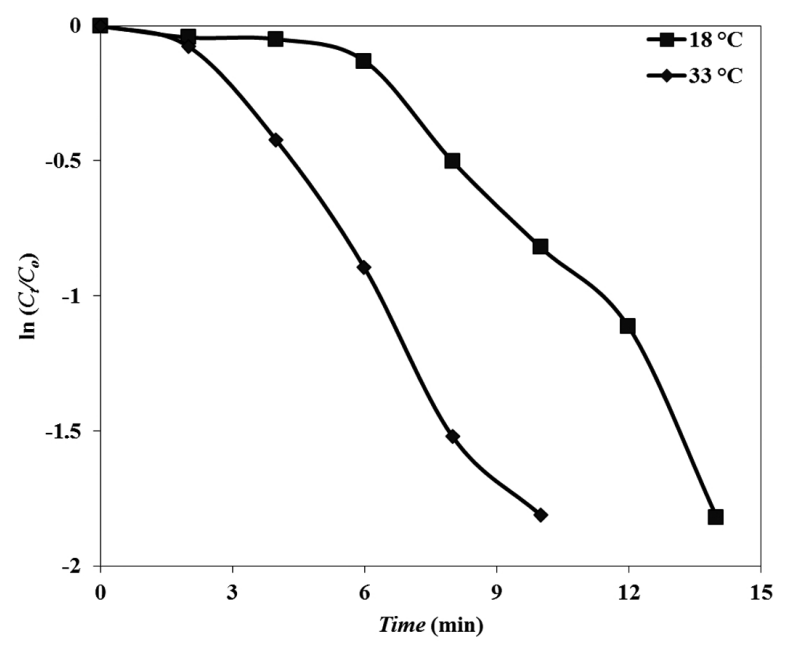

Fig. 6. Plot of $\ln \left(C_{t} / C_{o}\right)$ versus time for catalytic reduction of $\mathrm{NB}$ at different temperatures (conditions: $[\mathrm{NB}]=0.05 \mathrm{mM},\left[\mathrm{NaBH}_{4}\right]=5 \mathrm{mM}$ and $[\mathrm{Cu}-$ $\mathrm{p}$ (NIPAM-co-MAAc) $]=0.16 \mathrm{mg} / \mathrm{mL}$ with total volume $2.5 \mathrm{~mL}$ in cuvette).

temperature. The $\mathrm{Cu}$ nanoparticles fabricated microgels are cheap catalysts as compared to $\mathrm{Ag}, \mathrm{Au}$, $\mathrm{Pt}$ and Pd nanoparticles fabricated microgels. Thus, these have a potential to be used as effective catalysts on industrial scale.

\section{Acknowledgements}

The authors are grateful to the University of the Punjab, Lahore, Pakistan, for financial support under Research Project Grant for the Fiscal Year 2015 - 2016.

\section{References}

[1] Luo J.Y., Li W., Chen F., Chen X.X., DA Li W., Wu H. Y., Gao Y. J., Zeng Q. G., Sensor. Actuat. BChem., 197 (2014), 81.

[2] Lu L. M., Zhang X.B., Shen G.L., Yu R.Q., Anal. Chim. Acta, 715 (2012), 99.

[3] Nazzal A.Y., QU L., Peng X., XIaO M., Nano Lett., 3 (2003), 819. 
[4] Graf C., VAn BlaAderen A., Langmuir, 18 (2002), 524.

[5] Gierden A., Sanchez W., Zvyagin A.V., Zhao X., Ross J.A., Roberts M.S., J. Biomed. Opt., 13 (2008), 064031.

[6] Gao X., Wachs I.E., Catal. Today, 51 (1999), 233.

[7] Sharma G., Mei Y., LU Y., Ballauff M., IRRGANG T., Proch S., Kempe R., J. Catal., 246 (2007), 10.

[8] Manesh K.M., Gopalan A.I., LeE K.P., Komathi S., Catal. Commun., 11 (2010), 913.

[9] Khan S.R., Farooqi Z.H., Ajmal M., SiddiQ M., Khan A., J. Disper. Sci. Technol., 34 (2013), 1324.

[10] Pich A., KaraK A., Lu Y., Ghosh A.K., Adler H.-J. P., J. Nanosci. Nanotechno., 6 (2006), 3763.

[11] Mei Y., Sharma G., Lu Y., Ballauff M., DrechSLER M., IrRgang T., Kempe R., Langmuir, 21 (2005), 12229.

[12] Mei Y., Lu Y., Polzer F., Ballauff M., DrechSLER M., Chem. Mater., 19 (2007), 1062.

[13] WANG Y., WANG Y., LU J., Ji L., ZANG R., WANG R., Opt. Commun., 283 (2010), 486.

[14] Santhanalakshmi J., Parimala L., J. Nanopart. Res., 14 (2012), 1.

[15] Shah V., Dobiášová P., Baldrian P., Nerud F., Kumar A., Seal S., J. Hazard. Mater, 178 (2010), 1141.

[16] Stelzig S.H., Menneking C., Hoffmann M. S., Eisele K., BarciKowski S., Klapper M., MÜLlen K., Eur. Polym. J., 47 (2011), 662.

[17] Wu S.H., Chen D.H., J. Colloid Interf. Sci., 273 (2004), 165.

[18] Cioffi N., Ditaranto N., Torsi L., Picca R.A., de Giglio E., Sabbatini L., Novello L., TanTillo G., Bleve-Zacheo T., Zambonin P.G., Anal. Bioanal. Chem., 382 (2005), 1912.

[19] Park B.K., Jeong S., Kim D., Moon J., Lim S., KIM J. S., J. Colloid Interf. Sci., 311 (2007), 417.

[20] Sahiner N., OZay O., Curr. Nanosci., 8 (2012), 367.

[21] Chan G.H., Zhao J., Hicks E.M., Schatz G.C., VAN DUYNe R. P., Nano Lett., 7 (2007), 1947.

[22] Dong Y., Ma Y., Zhai T., Shen F., Zeng Y., Fu H., YAO J., Macromol. Rapid Comm., 28 (2007), 2339.

[23] Zhou J., Yang J., Zhang Z., LiU W., Xue Q., Mater. Res. Bull., 34 (1999), 1361.
[24] Farooqi Z.H., Khan S.R., Hussain T., BEgum R., Ejaz K., Majeed S., Ajmal M., Kanwal F., SidDIQ M., Korean J. Chem. Eng., 31 (2014), 1674.

[25] Farooqi Z.H., SiddiQ M., J. Disper. Sci. Technol., 36 (2015), 423.

[26] Naeem H., Faroogi Z.H., Shah L.A., SiddiQ M., J. Polym. Res., 19 (2012), 1.

[27] Farooqi Z.H., Khan H.U., Shah S.M., SIDDIQ M., Arab. J. Chem., (2013), (in print), DOI: 10.1016/j.arabjc.2013.07.031.

[28] Faroogi Z.H., Wu W., Zhou S., SiddiQ M., Macromol. Chem. Phys., 212 (2011), 1510.

[29] Majumder P.S., Gupta S., Water Res., 37 (2003), 4331.

[30] Cronin M., Gregory B., Schultz T. W., Chem. Res. Toxicol., 11 (1998), 902.

[31] Senadeera G., Kitamura T., Wada Y., Yanagida S., J. Photoch. Photobio. A, 164 (2004), 61.

[32] Xu S., Minteer S. D., ACS Catal., 4 (2014), 2241.

[33] Shumakovich G.P., Otrokhov G.V., Khlupova M.E., Vasileva I.S., Zaitseva E.A., Morozova O.V., YAROPOLOV A.I., RSC Adv., 4 (2014), 30193.

[34] Farooqi Z. H., Khan A., SiddiQ M., Polym. Int., 60 (2011), 1481.

[35] Ajmal M., Farooqi Z.H., SiddiQ M., Korean J. Chem. Eng., 30 (2013), 2030.

[36] LiU Y.Y., LiU X.Y., YAng J.M., Lin D.L., Chen X., ZHA L.S., Colloid. Surf. A, 393 (2012), 105.

[37] Luo Q., Guan Y., Zhang Y., SiddiQ M., J. Polym. Sci. Pol. Chem., 48 (2010), 4120.

[38] Zhou S., Chu B., J. Phys. Chem. B, 102 (1998), 1364.

[39] Kratz K., Hellweg T., Eimer W., Colloid. Surface. A, 170 (2000), 137.

[40] Zhang J., Xu S., Kumacheva E., J. Am. Chem. Soc., 126 (2004), 7908.

[41] Wu J., Zhao N., Zhang X., Xu J., Cellulose, 19 (2012), 1239.

[42] Wu S., Dzubiella J., Kaiser J., Drechsler M., Guo X., Ballauff M., Lu Y., Angew. Chem. Int. Edit., 51 (2012), 2229.

[43] Vadakkekara R., Chakraborty M., Parikh P. A., Colloid. Surface. A, 399 (2012), 11.

Received 2015-01-21 Accepted 2015-04-26 